\title{
A Hidrelétrica de Belo Monte como fator de segregação socioespacial: uma análise a partir da cidade de Altamira-PA
}

\section{The Belo Monte Dam as a factor of socio-spatial segregation: an analysis from the city of Altamira-PA}

Elisa Mergulhão Estronioli - Mestre em Geografia pela Universidade Federal Pará (UFPA). Militante do Movimento dos Atingidos por Barragens (MAB). E-mail: elisaestronioli@gmail.com

José Queiroz de Miranda Neto - Doutor em Geografia pela Universidade Estadual Paulista (UNESP). Professor do Programa de Pós-Graduação em Geografia (PPGEO) e da Faculdade de Geografia (FACGEO) da Universidade Federal do Pará (UFPA). E-mail: mirandaneto@ufpa.br

\section{Resumo}

A segregação socioespacial é um processo dialético indissociável da dinâmica do sistema capitalista nas cidades e expressa a luta de classes pela apropriação do espaço. Este artigo discute como a Hidrelétrica de Belo Monte, como um dos fatores de reestruturação na cidade de Altamira (PA), interfere no processo de segregação socioespacial. A construção do empreendimento hidrelétrico mobilizou uma grande quantidade de capital e de trabalhadores para a região, implicando diretamente no aumento dos preços de terrenos e dos aluguéis, influenciando processos de ocupação urbana em áreas alagadiças, como na Lagoa do Independente I. Além disso, a Norte Energia agiu diretamente em processos de reassentamento urbano, modificando as localizações urbanas da população mais pobre da cidade de Altamira no sentido centroperiferia. Como resultado, apresentamos dois modos de segregação: a conduzida, resultante dos programas de requalificação desenvolvidos pela empresa Norte Energia; e a induzida, que emerge a partir da ampliação da desigualdade socioespacial advinda de Belo Monte.

\section{Palavras-chave}

Segregação urbana. Hidrelétrica. Belo Monte. Altamira.

\begin{abstract}
Socio-spatial segregation is a dialectical process inseparable from the dynamics of the capitalist system in the cities and expresses the class struggle for the appropriation of space. This article discusses how the Belo Monte Hydroelectric Plant, by causing a restructuring in the city of Altamira (PA), interferes in the process of socio-spatial segregation. The construction of the hydroelectric project mobilized a large amount of capital and workers for the region, directly implying an increase in land and rental prices and influencing on processes of urban occupation in wetlands, as in the case of Lagoa do Independente I. Norte Energia acted directly in urban resettlement processes, modifying the urban locations of the poor population of the city of Altamira in the center-periphery direction. As a result, we present two modes of segregation: the conducted one, resulting from the requalification programs conducted by the Norte Energia company, and the induced one, which emerges from the expansion of sociospatial inequality arising from Belo Monte.
\end{abstract}

\section{Keywords}

Urban segregation. Hydroelectric plant. Belo Monte. Altamira. 


\section{INTRODUÇÃO}

Nessas primeiras décadas do século XXI, a humanidade vive um processo de urbanização em escala inédita. De acordo com a Organização das Nações Unidas (ONU), em 2014, 54\% da população mundial já estava vivendo em cidades e a tendência é que em 1950 a cifra atinja 66\% da população (ONU, 2019). Sob o sistema capitalista, conhece-se a mais drástica reestruturação do espaço geográfico já vivenciada (SMITH, 1988). O capital estrutura e reestrutura o espaço em todas as escalas, do mundial até o local, de forma que "nenhuma pedra feita por Deus permanece no lugar, nenhuma relação original com a natureza permanece inalterada, nenhum ser vivo deixa de ser afetado" (SMITH, 1988, p. 20).

Se a existência de cidades remonta a períodos muito antigos na história, o fenômeno da urbanização é relativamente recente, pois se relaciona com o modo de produção capitalista a partir de sua fase industrial, embora seja um equívoco considerar a urbanização como mero subproduto deste processo (LENCIONI, 2008).

No Brasil, considera-se que esse processo se intensifica a partir dos anos de 1930. Para Santos (2005), alcançamos, a partir do terceiro terço do século $\mathrm{XX}$, a urbanização da sociedade e a urbanização do território no Brasil, em um processo no qual, antes restrita a uma faixa litorânea, a urbanização generalizase (SANTOS, 2005, p. 9). Na virada da década de 1960 para 1970, ocorre uma inversão no lugar de residência da população brasileira. Em 1970, 56,8\% da população já é urbana. Esse processo não se dá de maneira uniforme em todo o território brasileiro, mas de forma desigual, criando lugares de maior densidade e outros de maior rarefação.

Nos períodos anteriores, em que a economia tinha uma base agrária, o lugar principal da produção era o campo e as cidades concentravam a função da circulação das mercadorias (mercado) e da presença de alguns equipamentos administrativos. Sob o capitalismo industrial, o urbano se torna o "espaço absoluto da produção" (SMITH, 1988, p. 197). No caso brasileiro, Santos (2005) afirma que a cidade deixa de ser aquela "dos notáveis" para ser eminentemente econômica.

A urbanização do território, em escala nacional, corresponde à urbanização da pobreza. Santos (2005) faz referência ao poder de atração da cidade sobre a população empobrecida no campo. Marx e Engels reportam, desde o século XIX, em plena revolução industrial, o potencial das cidades de atraírem uma massa de trabalhadores expropriados dos meios de produção, que vão se amontoar em condições precárias, para ficarem próximos dos locais de trabalho (SMITH, 1988). 
Nas cidades contemporâneas, os locais de moradia, de circulação e demais aspectos da reprodução social das distintas classes sociais nas cidades são modificados segundo as necessidades de acumulação do capital. Trata-se da época em que se passa da produção de mercadorias no espaço para a produção do próprio espaço como mercadoria (CARLOS, 2015). Esse processo é determinado por diferentes estratégias de valorização do solo urbano para exploração dos negócios imobiliários. Desse processo, emerge a segregação socioespacial não como uma externalidade, mas vinculada à própria produção da cidade capitalista.

No presente artigo, analisaremos como se deu esse processo em AltamiraPA, uma cidade média amazônica atingida pela Hidrelétrica de Belo Monte, usina que começou a ser construída em 2011 sob responsabilidade da empresa Norte Energia S.A (NESA). Essa obra mobilizou uma grande quantidade de capital e de trabalhadores para a região, implicando diretamente no aumento dos preços de terrenos e de aluguéis, forçando processos de ocupação urbana em áreas alagadiças, como o caso da baixada do bairro Jardim Independente I, comumente chamada Lagoa do Independente I. Além disso, a Norte Energia conduziu um processo de reassentamento das famílias atingidas pelo lago da hidrelétrica, modificando as localizações da população mais pobre no sentido centro-periferia.

Iniciaremos uma abordagem que trata da produção do espaço urbano e dos processos de segregação socioespacial na cidade capitalista, apresentando tal fenômeno como um componente constituinte da relação entre os agentes na produção de tal espaço, valendo-se de autores como Souza (2013), Smith (1988) e Maricato (2015). Na sequência, apresentaremos alguns aspectos da reestruturação da cidade de Altamira-PA em decorrência da instalação da usina hidrelétrica de Belo Monte, a partir de 2011, identificando dois modos em que se dá a segregação socioespacial: de maneira conduzৃida, resultante dos programas de reassentamento e requalificação urbana planejados pela empresa Norte Energia; e de maneira induzida, com a intensificação da ocupação de áreas ambientalmente frágeis no contexto de construção de Belo Monte.

\section{A PRODUÇÃO DO ESPAÇO URBANO E A CIDADE COMO NEGÓCIO}

O espaço da sociedade, que cobre toda a superfície da Terra (SOUZA, 2013), também é um produto do trabalho humano. Santos (2013) define o espaço como "um conjunto indissociável, solidário, mas também contraditório, de sistemas de objetos e sistemas de ações" (SANTOS, 2013, p. 106). Dessa forma, não é constituído apenas de sua materialidade (configuração espacial), mas também 
pelas relações sociais. Nessa mesma perspectiva, Souza (2013), citando Lefebvre, destaca a importância da produção do espaço, sobretudo o espaço urbano, para a acumulação capitalista (SOUZA, 2013, p. 39). Negri (2010, p. 130) diz que "cada vez mais a cidade é lugar de atuação dos agentes de produção do espaço".

Nesse caso, o solo urbano, como tudo que é produto do trabalho sob o capitalismo, torna-se igualmente mercadoria. Em sua complexidade, a cidade pode ser subdividida em suas "células básicas", que são "o espaço absoluto individual da propriedade privada". Cada um desses espaços "têm preço na forma de renda do solo" (SMITH, 1988, p. 200).

Harvey (2013) lembra que a terra urbana é uma mercadoria “especial”. O fato de que dois corpos não podem ocupar o mesmo lugar no espaço faz com que cada localização seja única. Uma vez que a propriedade privada da terra é uma das bases do capitalismo, é possível falar em monopólio da terra urbana, que permite ao proprietário extrair riqueza na forma de renda. "A propriedade privada da terra [...] estabelece claramente a porção da superfície da terra sobre a qual indivíduos privados têm poder monopolistas exclusivos” (HARVEY, 2013, p. 438).

Em diálogo com esse pensamento, Maricato (2015) afirma que a terra urbana está sempre na condição de monopólio, constituindo-se em uma "mercadoria especial que tem o atributo de captar ganhos sob a forma de renda" (MARICATO, 2015, p. 23). Este atributo possibilita que o espaço urbano seja ele mesmo mercantilizado ou, nas palavras da autora, que a cidade se torne um negócio: "a cidade é um grande negócio e a renda imobiliária, seu motor central" (MARICATO, 2015, p. 23).

No entanto, se a cidade é mercadoria para a classe proprietária, tendo como ênfase o seu valor de troca, ela é meio de vida para a classe despossuída, que enfatiza o seu valor de uso. Desse modo, "entre o valor de troca da cidade mercadoria e o valor de uso da cidade condição necessária de vida para a classe trabalhadora, há uma profunda oposição que gera um conflito básico" (HARVEY, 1982 apud MARICATO, 2015, p. 24).

O espaço urbano aparece como local de produção, mas também reprodução da força de trabalho. Para essa reprodução, o consumo é fundamental, pois, uma vez que o trabalhador urbano é despido da condição de produção de seus próprios meios de subsistência, tudo que necessita é mediado pelo consumo de mercadorias. É em busca de melhores condições para o consumo do espaço urbano que Villaça (1998) afirma que se dá a luta de classes na cidade.

Citando Castells, Villaça (1998) lembra que o espaço urbano é produto do trabalho humano (VILLAÇA, 1998). As classes lutam pela apropriação deste espaço enquanto produto do trabalho. A disputa por localização no meio urbano 
é, assim, expressão da luta de classes. Nessa luta, a burguesia molda a cidade conforme seus interesses, escolhendo onde morar e controlando o mercado de terras (essa mercadoria especial) e outros setores estratégicos para a produção do espaço urbano, como a construção civil. Corrêa (1989) lembra que, por esse mecanismo, as classes dominadas são submetidas a um processo de segregação imposto pelas classes dominantes, como afirma:

A classe dominante, ou uma de suas frações [...] segrega os grupos sociais na medida em que controla o mercado de terras, a incorporação imobiliária e a construção, direcionando seletivamente a localização dos demais grupos sociais no espaço urbano (CORREA, 1989, p. 64).

O autor afirma, assim, que “a segregação residencial é uma expressão espacial das classes sociais" (CORRÊEA, 1989, p. 61). Villaça (1998), por sua vez, lembra que não se trata de dois movimentos ocorrendo de maneira independente, uma autossegregação das classes dominantes e um processo de segregação das classes dominadas, mas um só processo dialeticamente articulado: "a segregação é um processo dialético, em que a segregação de uns provoca, ao mesmo tempo e pelo mesmo processo, a segregação de outros. Segue a mesma dialética do escravo e do senhor" (VILLAÇA, 1998, p. 148).

A segregação socioespacial urbana é um processo claramente visível nas grandes metrópoles, mas, como processo inerente ao capitalismo, existe também nas pequenas e médias cidades, apresentando-se de forma mais ou menos evidente. Tal processo não se refere apenas à distribuição das classes no espaço urbano, mas é permeado por relações de poder. Segundo Villaça (1998, p. 150), "a segregação é um processo necessário à dominação social, econômica e política por meio do espaço".

Por meio da segregação, as classes dominantes exercem o controle do espaço e reduzem as possibilidades de ascensão social de membros da classe trabalhadora. Além disso, quem vive nesses espaços tem menos acesso a serviços públicos e sofre estigmatização (NEGRI, 2010).

O Estado cumpre um papel essencial nesse processo, uma vez que direciona recursos públicos para os bairros de alta renda. Por intermédio do Estado, as burguesias atuam "indiretamente" para valorizar partes escolhidas do espaço urbano (CORRÊEA, 1989). Tal infraestrutura urbana produz e reproduz desigualdades (NEGRI, 2010), criando uma espiral em que a distribuição desigual das classes no espaço causa o aumento das diferenças sociais.

Harvey (1980) observa que, desde o início da revolução industrial, a construção de habitações para a classe trabalhadora nunca despertou o interesse 
da burguesia ligada à construção. No Brasil, as políticas habitacionais voltadas para a classe trabalhadora são exceção, como afirma Maricato (2015):

A habitação dos trabalhadores não é problema para o capital e, na maior parte das vezes, nem para o Estado. Por isso, os bairros de moradia dos trabalhadores são construídos por eles mesmos, nos seus horários de descanso ("autoconstrução"). E, também por isso, as favelas fazem parte do processo de reprodução da força de trabalho formal (MARICATO, 2015, p. 20).

A técnica de autoconstrução utilizada pelas classes populares integra a reprodução da força de trabalho, constituindo-se em trabalho não pago. Ela contribui para o rebaixamento geral dos salários. Por isso, Maricato (2015) faz menção a uma urbanização dos baixos salários para se referir à forma como os mais pobres se integram à produção do espaço urbano.

Em suma, a segregação socioespacial no espaço urbano, processo dialético que leva a massa de trabalhadores a viveram em condições de precariedade, é estruturante das cidades no capitalismo. Nesse espírito, Souza (2003) considera incorreto falar em exclusão no que se refere aos bairros populares, como se estes não fizessem parte da cidade, pois se corre o risco de esquecer que "a maioria dos pobres urbanos está integrada econômica, política e culturalmente ao sistema, enquanto trabalhadores explorados, consumidores de baixo poder aquisitivo e eleitores" (SOUZA, 2003, p. 69).

Entende-se, desse modo, que a cidade capitalista se configura essencialmente de modo desigual e os processos de segregação são a expressão das relações de classe materializadas na (re)produção desses espaços. Na seção a seguir, será discutido como a instalação de um grande empreendimento hidrelétrico em uma cidade amazônica acaba, mediante circunstâncias específicas de atuação do capital, reforçando essa tendência.

\section{BELO MONTE E A SEGREGAÇÃO EM ALTAMIRA}

No estudo da desigualdade territorial no Brasil, Santos e Silveira (2008) identificam "zonas de densidade e zonas de rarefação", não em sentido especificamente demográfico, mas "quanto às coisas, aos objetos, aos homens, ao movimento das coisas, dos homens, das informações, tanto do dinheiro e também quanto às ações" (SANTOS; SILVEIRA, 2008, p. 260). Os autores citam, ainda, os binômios reveladores dessa desigualdade: espaços de fluidez e espaços viscosos, da rapidez e da lentidão, luminosos e opacos, espaços que mandam e que obedecem. 
A Amazônia, nessa perspectiva, inclui-se entre as "regiões de rarefações demográficas herdadas e baixas densidades técnicas" (SANTOS; SILVEIRA, 2008, p. 274). Os autores usam a metáfora das áreas luminosas e opacas - em que as luminosas são as de alta densidade técnica, onde se vê, em imagens de satélite noturnas, a energia elétrica concentrada em grandes centros urbanos. Irônico que o destino do fornecimento de energia elétrica da "opaca" Amazônia seja, justamente, "iluminar" as regiões de maior densidade demográfica e técnica do país. O setor elétrico, inclusive, evidencia a separação entre os espaços de mandar e de fazer, pois o lugar da produção da energia elétrica difere do lugar do comando político e técnico e do consumo dessa mercadoria.

Ao analisar a presença dos projetos de grande porte como expressão do meio técnico científico-informacional, Trindade Júnior (2010) afirma que, se por um lado é marcante o significado das novas dinâmicas urbanas na vida local, por outro "coloca-se a necessidade de uma análise crítica das cidades dos 'grandes objetos', no que diz respeito à relação que historicamente elas têm apresentado face a essas realidades locais" (TRINDADE JÚNIOR, 2010, p. 137).

Essa é a lógica da Usina Hidrelétrica de Belo Monte, um projeto cercado de polêmicas, cujos primeiros estudos remontam à década de 1970, mas sua implantação tornou-se possível somente no início da segunda década do século XXI. Instalada no curso médio do rio Xingu, no Pará, Belo Monte constitui-se um evento que provoca intensas mudanças na região onde se instala, inclusive na cidade de Altamira-PA.

A região que se encontra sobre influência da usina é marcada, em princípio, pela representatividade histórica do rio Xingu como fio condutor da dinâmica econômica e social dos povos que, a partir dele, constituíram seu modo de vida, como indígenas e ribeirinhos. Entretanto, como assegura Acevedo Marin (2010), muitas das mudanças que se operam acabam promovendo a "destruição de toda uma série de formações mais antigas de produção, organização social e cultural; de conformação de novos e diversos processos sociais de territorialização; de redimensionamentos de espaços físicos" (ACEVEDO MARIN, 2010, p. 4). Sobretudo após a década de 1970, essas remodelações físicas se deram, como sugere Becker (2013), a partir de "surtos industrializantes", integrando espaços urbanos e rurais às lógicas de uma racionalidade externa.

Fundada como vila em 1883 e elevada à condição de município em 1911, Altamira surge como local de missões jesuíticas e aldeamentos e posteriormente consolida-se como entreposto do escoamento da borracha (UMBUZEIRO; UMBUZEIRO, 2012). Conforme aponta Castro (2008, p. 17), “com a ascensão da economia da borracha, a malha de produção e troca de mercadorias estendeu- 
se por um território maior, abrindo novas áreas de povoamento". Nessa fase, a cidade viveu um período de típica localidade ribeirinha, cuja dinâmica dependia do rio como via principal de transporte e comunicação. Com a decadência do ciclo econômico da borracha, Altamira viveu um período de estagnação das atividades ligadas à exportação, sobrevivendo da caça, da agricultura e do extrativismo local.

A partir dos anos de 1970, a abertura da rodovia Transamazônica (BR-230), megaempreendimento do governo ditatorial militar, transforma radicalmente a estrutura da cidade, determinando um novo eixo de desenvolvimento e a expansão da malha urbana. De acordo com Castro (2008):

O modelo estratégico aplicado para abrir novos territórios ao mercado integrou antigas cidades - notadamente as pequenas, mas com influência regional devido às práticas tradicionais de organização da economia e das relações com a interland rural - ao povoamento induzido pelos planos governamentais. São exemplos cidades como Porto Velho e Rio Branco, Altamira, Itaituba, Santarém, Marabá, Tucuruí e São Felix do Xingu (CASTRO, 2008, p. 23).

Como principal centro urbano regional nas áreas entre o rio Xingu e a rodovia Transamazônica, Altamira torna-se o ponto de chegada de uma nova corrente migratória. O Projeto Integrado de Colonização (PIC) estabeleceu as bases para a colonização de lotes rurais ao longo da rodovia, mas, posteriormente, a concentração de terras e os conflitos fundiários contribuíram para a expulsão de parte dos trabalhadores do campo e o aumento da população urbana nas décadas de 1970 e 1980.

Essas limitações do processo de colonização dirigida são uma característica desse período na Amazônia. Becker (1990, p. 38) apontou que a fronteira na Amazônia no período dos projetos de migração induzida pelo Estado possui característica urbana, como estratégia de ocupação e controle da força de trabalho. Foi nesse período que o município viveu seu maior crescimento proporcionalmente à população, que "triplicou entre 1970 e 1980, passando de 15.345 para 46.509, respectivamente. O crescimento da população urbana é, também, significativo, passando de 5.905 em 1970 para 26.926 em 1980" (MIRANDA NETO; HERRERA, 2016, p. 4).

Ao final de 1980, contudo, tal empreendimento já apresentava sinais de esgotamento, sobretudo por conta do "fim do crédito agrícola subsidiado e com a queda brutal dos preços agrícolas no mercado interacional” (HÉBETTEE, 2002, p. 223). O efeito de tal processo são as migrações rural-urbanas, uma vez que a população urbana passa de 26.926 habitantes em 1980 para 54.235 em 1996. Esse rápido crescimento marcou o novo papel da cidade de Altamira como centro de absorção da população migrante, como destacam Alonso e Castro (2006): 
É importante destacar que a década de 1980 foi um período em que muitos colonos abandonaram seus lotes na Transamazônica, sendo a cidade de Altamira uma das principais escolhas de destino desses migrantes. Nesse período, novos bairros aparecem, contudo, a estrutura da cidade era deficiente (ALONSO; CASTRO, 2006, p. 190).

Com o aumento da população, evidenciam-se os limites na ocupação da terra urbana e verifica-se o início da ocupação das áreas de várzea ao longo do rio Xingu e dos igarapés Altamira e Ambé, chamados pela população local de baixões. Trata-se de um processo de autoconstrução de habitações, em geral de madeira, construídas sobre palafitas e sujeitas às alagações sazonais no período das cheias, que corresponde ao período mais chuvoso na região (inverno amazônico).

De acordo com o censo de 2010, a população vivendo em "aglomerados subnormais" em Altamira correspondia a mais de nove mil pessoas (MIRANDA NETO, 2014). Esses assentamentos irregulares se caracterizam pela ausência de saneamento, alta densidade demográfica e escassez de serviços públicos. Tratase de uma solução popular para o problema da moradia recorrente nas cidades brasileiras. Segundo Maricato (2015):

As áreas ambientalmente frágeis - beiras de córregos, rios e reservatórios, encostas íngremes, mangues, áreas alagáveis, fundos de vale -, que, por esta condição, merecem legislação específica e não interessam ao mercado legal, são as que "sobram" para a moradia de grande parte da população. As consequências dessas gigantescas invasões são muitas: poluição dos recursos hídricos e mananciais, banalização de mortes por desmoronamentos, enchentes, epidemias etc. (MARICATO, 2015, p. 82).

Consolidam-se, assim, processos de ocupação urbana tipicamente amazônicos em Altamira-PA, em áreas de várzea, sujeitas a alagamentos periódicos. Nessa situação, a habitação de palafita com característica ribeirinha ganha significado de precariedade, em um contexto no qual o rural e o urbano se entremeiam e se confundem mediados pelo rio e seu movimento.

Quando Belo Monte se instala, desencadeia-se um processo de reestruturação urbana que incide sobre este quadro. Por um lado, mediante o "Projeto de Requalificação Urbana" (NORTE ENERGIA, 2011), Belo Monte provoca diretamente o deslocamento da população mais pobre no sentido centroperiferia, ao retirar os moradores dos locais reservados à formação do reservatório da hidrelétrica e transferi-los para conjuntos habitacionais construídos para este fim.

Por outro lado, Belo Monte provoca uma rápida valorização no preço da terra urbana, impedindo ou dificultando o acesso de famílias com menos recursos em um momento no qual a cidade vive um rápido aumento populacional motivado pela hidrelétrica. Assim, contraditoriamente, ao mesmo tempo em que 
a empresa remove as pessoas das áreas alagadiças, também induz à ocupação dessas áreas devido à pressão sobre o mercado imobiliário.

Dessa forma, nos primeiros anos de implantação da hidrelétrica, é possível notar ao menos esses dois efeitos no processo de segregação provocados na cidade de Altamira pela hidrelétrica.

\subsection{OS REASSENTAMENTOS URBANOS COLETIVOS (RUC) E A SEGREGAÇÃO CONDUZIDA}

Ao longo dos Igarapés Altamira, Ambé e Panelas, assim como na orla do Xingu, os responsáveis pela usina de Belo Monte decretaram a existência da "Área Diretamente Afetada" (ADA), ou seja, a área sujeita ao alagamento decorrente da formação do reservatório da hidrelétrica (ELETROBRÁS, 2010). O nível do reservatório chegaria até a cota 97 com relação ao nível do mar, sendo estabelecida a cota 100 como margem de segurança. O conjunto dessas áreas abarca cerca de $1 / 4$ da malha urbana de Altamira (MIRANDA NETO, 2014). Esse perímetro foi declarado como área de utilidade pública e a população foi forçadamente retirada mediante "critérios de elegibilidade" (NORTE ENERGIA, 2011) que previam formas de tratamento como indenização em dinheiro ou reassentamento, dependendo de cada caso.

Como se trata de uma remoção de moradores que, em geral, estavam próximos e dependiam do rio, entende-se que esse processo se assemelha, em parte, ao fenômeno de segregação que ocorreu em algumas metrópoles como Belém e, de modo semelhante, em algumas cidades médias amazônicas. O processo em análise, apesar de possuir motivações relacionadas à instalação de uma hidrelétrica e suas ações condicionantes, também separou a população mais pobre do rio. A esse respeito, cabe a argumentação de Trindade Júnior (1998) ao analisar a transferência das populações das baixadas urbanas para os subúrbios em Belém, quando afirma que:

Quando ainda morador destas, sente uma de suas principais perdas que é exatamente a do rio que muitas vezes "comandou sua vida", já que nas margens dos igarapés que cortam a cidade ele não pode mais usufruir desse recurso hídrico, seja para a sua alimentação, seja como via de circulação, ou mesmo como espaço de lazer (TRINDADE JÚNIOR, 1998, p. 48).

A citação de Trindade Júnior (1998) aborda esse contexto de separação da população em relação ao rio e suas perdas decorrentes, uma vez que muitos moradores viviam da pesca e realizavam atividades de lazer nas proximidades de suas residências e foram removidos de forma compulsória. 
A Norte Energia, concessionária da hidrelétrica, inicialmente construiu cinco loteamentos (Reassentamentos Urbanos Coletivos - RUC) como política de compensação para realocar parte dos atingidos, com um total de 3.700 unidades habitacionais, que chegaram a abrigar uma população de 3.573 famílias reconhecidas pela empresa (sem contar mudanças espontâneas) até março de 2017 (NORTE ENERGIA, 2017). Posteriormente, sob cobrança dos movimentos sociais, foi construído mais um reassentamento, com 150 unidades habitacionais, especificamente para população indígena e ribeirinha. Na Figura 1, apresenta-se a localização das áreas de Reassentamento Urbano Coletivo (RUC) e como estão dispostas na cidade de Altamira.

Figura 1 - Localização dos Reassentamentos Urbanos Coletivos (RUC) em Altamira - Pará

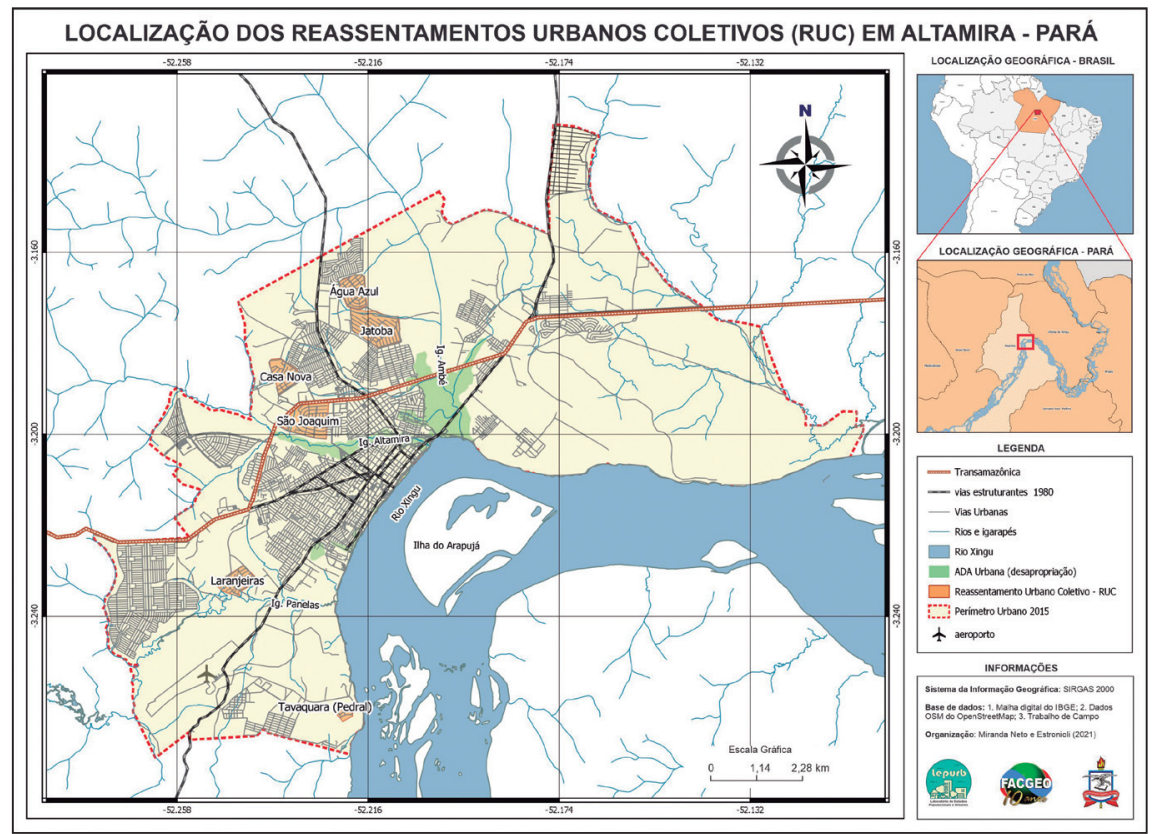

Organizado por Miranda Neto e Estronioli, 2021.

Nesses reassentamentos, foram construídas habitações padrão de $63 \mathrm{~m}^{2}$, em terrenos de $300 \mathrm{~m}^{2}$. As casas foram feitas em concreto injetado, o que permitiu redução de custos e diminuição no tempo de construção para a empresa. Os RUC também contam com ruas pavimentadas, calçamento, iluminação pública, rede de abastecimento de água e coleta de esgoto. Possuem alguns equipamentos públicos, como postos de saúde, escolas e creches, dependendo do tamanho e da distância desses serviços. 
Esses loteamentos, em geral, receberam famílias cujas indenizações (caso viessem a receber em dinheiro ou em carta de crédito) seriam insuficientes para adquirir uma moradia considerada adequada no mercado imobiliário de Altamira. Os RUC receberam, também, pessoas que não tiveram direito à indenização, como famílias posseiras e agregadas. Portanto, não se tratou exatamente de uma opção, embora assim fosse apresentada às famílias. Por conta dessa lógica compulsória de deslocamento, utiliza-se aqui a expressão "segregação conduzida", pois o reassentamento se tornou um caminho de via única para parte das pessoas removidas em função da intervenção urbana decorrente da instalação da usina de Belo Monte.

Na Figura 1, observa-se a localização dos RUC, todos na periferia, relativamente afastados do centro da cidade e do rio Xingu, à exceção do RUC Tavaquara (o mais distante do centro urbano, porém próximo ao rio), construído nas condições citadas anteriormente. Assim, conforma-se um processo de segregação em termos de centro-periferia (talvez o mais tradicional modo de segregação nas cidades). Mas, paradoxalmente, apresenta-se como forma de integração ao espaço urbano, já que os atingidos pela hidrelétrica deixaram de viver em locais de habitação precária em áreas alagadiças e passaram a morar em um bairro planejado, com infraestrutura. Ressalta-se que essa mensagem positiva foi intencionalmente elaborada pela empresa, em suas peças de propaganda.

A promessa do reassentamento era de mais qualidade de vida para as famílias atingidas. Uma pesquisa feita pela Fundação Viver, Produzir e Preservar (FVPP, 2017), no entanto, apontou algumas contradições desse processo. A pesquisa entrevistou 951 moradores dos cinco reassentamentos para medir o nível de satisfação com relação às condições de moradia anteriores à realocação. Foram avaliados os itens: moradia, abastecimento de água, energia elétrica, saneamento, cultura e lazer, segurança pública, comércio local, arborização, organização dos moradores, serviços bancários, serviços de saúde, assistência social, educação, mobilidade e transporte público, iluminação e acessos.

Destes, apenas "moradia" e "saneamento" apresentaram resultado satisfatório $(62 \%$ e $58 \%$ dos entrevistados consideram que a situação atual melhorou com relação à moradia anterior). Isso revela uma avaliação positiva quanto à qualidade das edificações, em comparação com a situação anterior. Já "saneamento", na pesquisa, refere-se à constatação de que nas habitações anteriores, usualmente, não havia rede de esgoto, que era despejado diretamente nos cursos d'água.

O abastecimento de água, por sua vez (tratado de maneira separada do saneamento na pesquisa), é apontado como pior que antes por 57\% dos 
entrevistados. De fato, a falta de água é uma reclamação comum entre os moradores dos reassentamentos e com alguma frequência aparece na imprensa local, além de ser tema de reivindicação dos movimentos populares (MAB, 2021).

Chama atenção, no entanto, que todos os outros itens tenham sido considerados piores do que antes por mais de 50\% dos entrevistados (FVPP, 2017). A avaliação dos itens de forma negativa evidencia problemas relacionados especialmente à distância de serviços essenciais. A maior insatisfação é com relação ao item "serviços bancários": tendo em vista que este serviço é praticamente concentrado na região central da cidade, $88 \%$ dos entrevistados consideraram que piorou. A “mobilidade e o transporte público" também foram avaliados negativamente, uma vez que o processo de segregação do tipo centroperiferia tornou os percursos bem mais longos.

\subsection{OCUPAÇÃO DE BAIXÕES E LAGOAS: A SEGREGAÇÃO INDUZIDA}

Após a remoção das famílias atingidas, o rio Xingu (agora reservatório da hidrelétrica) e os igarapés que cortam a cidade, bem como os locais às suas margens, sofreram intervenções de "requalificação urbana", sendo criados parques com áreas verdes e equipamentos de lazer (NORTE ENERGIA, 2011). Durante o auge da construção da hidrelétrica, esses locais se transformaram em uma área institucionalmente protegida pelo Estado e pela Norte Energia, contando inclusive com vigilância patrimonial para evitar que os moradores voltassem ou novas famílias os ocupassem.

O que antes era o território usado pela população, o território "abrigo" de Milton Santos, agora se tornou território "recurso" (SANTOS, 2002) - com o objetivo da extração de lucros obtidos através da geração da energia hidrelétrica. Ou, ainda, o que era território usado, "espaço banal” ou espaço habitado, tornase território em rede, cujo centro de comando está distante e o funcionamento é ditado por uma lógica de verticalidades, submetido à "racionalidade do Mercado (Mundo)" (SANTOS, 2013).

No mesmo período, a demanda por moradia cresceu em Altamira. A população do município saltou de cerca de 99 mil para quase 150 mil habitantes, devido à migração de trabalhadores atraídos no auge da construção civil da hidrelétrica (MIRANDA NETO; HERRERA, 2016).

Esse processo provocou uma desestruturação no mercado imobiliário, com aumento excessivo no preço dos imóveis (MIRANDA NETO; HERRERA, 2016). Adicionalmente, a empresa teve um atraso no cronograma da construção 
dos alojamentos dos operários, o que contribuiu ainda mais para pressionar o mercado imobiliário local.

Diante desse cenário, famílias pobres que já residiam na área urbana de Altamira foram induzidas a se mudarem para ocupações precárias, principalmente em áreas alagadiças. Famílias migrantes que chegavam à cidade em busca de trabalho nas obras da hidrelétrica, também, por vezes, se estabeleceram nestes locais. Este é o segundo processo de segregação a que nos referimos como desencadeado pelo evento Belo Monte na cidade de Altamira. Dessa forma ocorre:

Uma tendência de uso do solo urbano para fins de obtenção de lucros, encarecendo os preços dos terrenos e aluguéis e, por consequência, gerando a exclusão das populações mais pobres que vivem e trabalham na cidade. Tem-se, com isso, a produção acelerada de habitações irregulares, notadamente no leito dos igarapés e áreas pouco valorizadas do ponto de vista econômico (MIRANDA NETO; ALVAREZ, 2017, p. 4).

Note-se que essa pressão urbana, além de ser prevista nos estudos da hidrelétrica, não é inédita no histórico do setor elétrico brasileiro, em especial na Amazônia. Cita-se o exemplo da cidade de Tucuruí, que também viveu, durante as fases de construção da hidrelétrica de mesmo nome, um grande afluxo populacional que ensejou "o surgimento de formas e dinâmicas espaciais espontâneas em razão do impacto causado pelo grande projeto" (ROCHA, 2008, p. 293). Isso porque, ainda de acordo com esse autor:

A estrutura urbana do núcleo preexistente, incapaz de acolher o surto populacional, levou à reprodução de condições de vida precárias, acompanhadas de todas as mazelas sociais: pobreza, prostituição, violência. A construção da usina hidrelétrica e dos núcleos urbanos de apoio, ao mobilizar grande quantidade de força de trabalho e atrair grande afluxo populacional, deu à cidade de Tucuruí uma nova configuração urbana, imprimindo-lhe uma nova dinâmica espacial (ROCHA, 2008, p. 293).

No caso de Altamira, portanto, intensificaram-se ocupações em áreas alagadiças onde já havia casas de palafitas, como o caso da lagoa do bairro Jardim Independente I. Embora com essas características, o local não era considerado parte da ADA de Belo Monte, devido à localização acima da cota 100: "tendo em vista que as áreas próximas os Igarapés Altamira, Ambé e Panelas estavam sob tutela da Norte Energia, as populações excluídas identificaram na lagoa do Independente I um canal aberto para a ocupação" (MIRANDA NETO; ALVAREZ, 2017, p. 4). A Figura 2 apresenta a localização da Lagoa do Independente I na cidade de Altamira. 
Figura 2 - Localização da Lagoa do Independente I

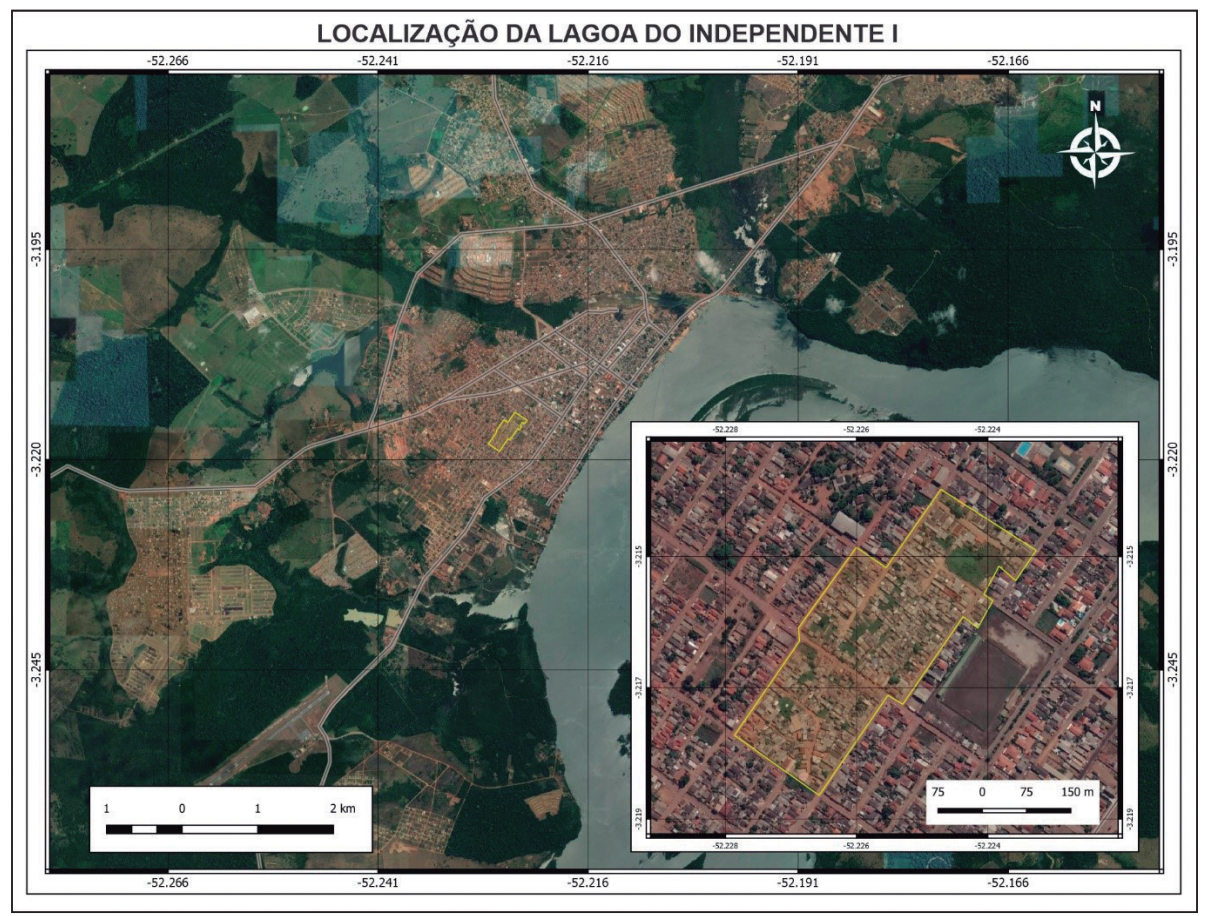

Elaborado com base no Google Earth e em localizações obtidas em atividade de campo, 2020.

Tal processo se assemelha ao que Souza (2003) denomina "segregação induzida" que, muito embora tenha semelhanças em relação à primeira no que diz respeito às condições de renda da população, não parte de um planejamento e ocorre sem qualquer tipo de assistência ou controle por parte do Estado ou da Norte Energia.

Imagens de satélite obtidas pelo Google Earth mostram momentos do processo de ocupação da área da lagoa do Independente I (Figura 3). Em 2005, havia ainda poucas casas no local, que aparece com cobertura vegetal. Cortando a lagoa, já é possível ver o traçado inicial do que seria a Rua Acesso 3. Implantada pela prefeitura, a via também contribuiu para a ocupação do local (IBAMA, 2018).

Em 2014, quando a construção da hidrelétrica chega ao auge, é visível o aumento no número de edificações e a diminuição da cobertura vegetal. Também se nota a construção de aterros nas laterais da lagoa, sobre os quais foram construídas casas majoritariamente de alvenaria. Naquele período, a Norte Energia iniciava a remoção dos moradores da ADA Urbana. 
Em 2017, tem-se o momento de maior adensamento da ocupação da lagoa. Nesse período, a Norte Energia dava por encerrado o processo de remoção dos atingidos da ADA, bem como as mudanças para os reassentamentos (NORTE ENERGIA, 2017).

Figura 3 - Lagoa do Independente I em diferentes momentos

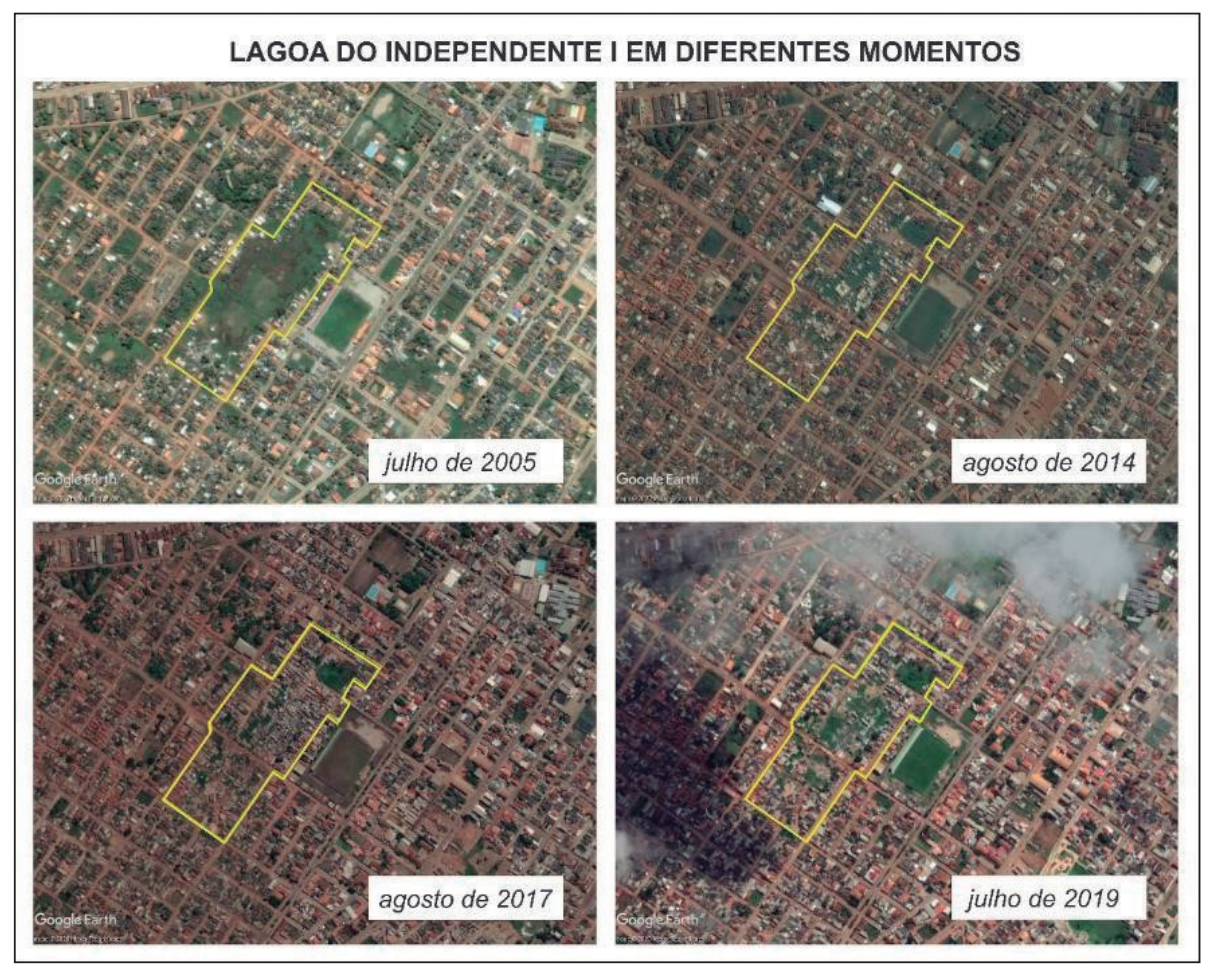

Elaborado com base no Google Earth e em localizações obtidas em atividade de campo, 2020 .

A correlação entre o fenômeno do aumento no preço dos aluguéis e a ocupação da lagoa do Independente I foi indicada por meio de um levantamento socioeconômico que o Ibama obrigou a Norte Energia a realizar, em uma conjuntura na qual os moradores empreendiam um processo de mobilizações pelo reconhecimento como atingidos pela hidrelétrica, organizados pelo Movimento dos Atingidos por Barragens (MAB). Em parecer, o Ibama afirma:

[...] a intensificação da ocupação da área da lagoa, observada a partir de 2010, guarda relação direta com a implantação da UHE Belo Monte. O cadastro mostra que o principal motivo para a ocupação daquele local a partir de 2010 foi o aumento da especulação imobiliária (impacto previsto no Estudo de Impacto Ambiental da UHE Belo Monte) (IBAMA, 2018, p. 18). 
Assim, as famílias da Lagoa do Independente I foram reconhecidas como atingidas por Belo Monte por um critério diferente do utilizado anteriormente, sem relação com a $\mathrm{ADA}$, mas com relação direta com o aumento no custo da habitação em Altamira, ligado ao processo de segregação socioespacial provocado no contexto de implantação da hidrelétrica.

A última imagem da Figura 3, referente ao mês de julho de 2019, já apresenta efeitos da remoção das edificações da localidade, com ocupação menos densa se comparada a agosto de 2017, inclusive com a retomada da vegetação na área.

A realocação dessas famílias, que ocorreu mediante indenização ou reassentamento, foi fruto de um intenso processo de lutas organizado pelo MAB, cujo desfecho exigiu negociação e divisão de responsabilidades entre a empresa e a prefeitura municipal. Até julho de 2019, quando a empresa considerou encerrada a remoção dos moradores, haviam sido contabilizadas 595 famílias removidas da localidade.

\section{CONSIDERAÇÕES FINAIS}

As dinâmicas da construção de hidrelétricas e de outros "grandes objetos" (SANTOS, 2013, p. 109) na Amazônia são elementos decisivos que, não raro, tornam-se vetores de complexas reestruturações espaciais. Dez anos após o início da construção de Belo Monte, Altamira ainda se encontra em processo de transformações. A natureza das intervenções na cidade, que combinam processos dirigidos e processos não planejados, interferiu ou acelerou o processo de segregação socioespacial que se apresentava de maneira menos complexa anteriormente.

Entendida como um evento que provoca a reestruturação da cidade de Altamira, Belo Monte interfere, entre outros processos, nas dinâmicas de segregação socioespacial. Um dos impactos mais marcantes é que Belo Monte muda o endereço das famílias mais pobres: expulsa famílias que ocupavam as áreas de várzea ou baixões, em um processo inicial de segregação, e as re-segrega nos reassentamentos, sob aparência de integração ao espaço urbano. Por outro lado, ao provocar um aumento no custo da moradia, intensifica a ocupação de áreas alagadiças que não estavam sob o controle direto da hidrelétrica, a exemplo da Lagoa do Independente I.

Impedir esse processo, ou ao menos reduzir seus efeitos negativos, exigiria atuação do Estado, com políticas públicas especificamente voltadas para este objetivo. Porém, se a segregação é estruturante nas cidades capitalistas 
e a mercantilização do espaço urbano é a regra, ações políticas que vão de encontro a essa tendência tornam-se exceções e, quando ocorrem, tendem a ser pouco abrangentes.

\section{REFERÊNCIAS}

ACEVEDO MARIN, R. E. Visão histórica da região do rio Xingu: economia e diversidade étnica. Papers do NAEA, Belém, n. 276, p. 4-22, dez. 2010.

ALONSO, S.; CASTRO, E. Processo de transformação e representações do rural-urbano em Altamira. In: CARDOSO, A. C. D. (org.). O rural e o urbano na Amazônia: diferentes olhares em perspectiva. Belém: EDUFPA, 2006. p. 161-215.

BECKER, B. K. Amazônia. São Paulo: Ática, 1990.

BECKER, B. K. A urbe amazônida. Rio de Janeiro: Garamond, 2013.

CARLOS, A. F. A. A condição espacial. São Paulo: Contexto, 2015.

CASTRO, E. Urbanização, pluralidade e singularidades das cidades amazônicas. In: CASTRO, E. (org.). Cidades na floresta. São Paulo: Annablume, 2008. p. 13-39.

CORRÊA, R. L. O espaço urbano. São Paulo: Ática, 1989.

ELETROBRÁS. Aproveitamento Hidrelétrico (AHE) Belo Monte: Estudo de Impacto Ambiental (EIA). Brasília, DF: Eletrobrás, 2010.

FVPP. A voz dos atingidos por Belo Monte: desafios e direitos. Altamira: FVPP, 2017.

HARVEY, D. A justiça social e a cidade. São Paulo: HUCITEC, 1980.

HARVEY, D. Os limites do capital. São Paulo: Boitempo, 2013.

HÉBETTE, J. Reprodução social e participação política na fronteira agrícola paraense: o caso da Transamazônica. In: HÉBETTE, J.; MAGALHÃES, S. B.; MANESCHY, M. C. (org.). No mar, no rio e na fronteira: faces do campesinato no Pará. Belém, EDUFPA, 2002. p. 203-231.

IBAMA. Parecer Técnico no 14/2018 - COHID/CGTEF/DILIC. Altamira: IBAMA, 2018. Disponível em: http://www.ibama.gov.br/sistemas/sei-ibama. Acesso em: 10 set. 2021.

LENCIONI, S. Observações sobre o conceito de cidade e urbano. GEOUSP: espaço e tempo (online), São Paulo, n. 24, p. 109-123, 2008. 
MAB. MAB cobra direito à água para os atingidos por Belo Monte. Movimento dos Atingidos por Barragens, São Paulo, 15 out. 2021. Disponível em: https:/ / mab.org.br/2021/10/15/mab-cobra-direito-a-agua-para-os-atingidos-por-belomonte/. Acesso em: 18 out. 2021.

MARICATO, E. Para entender a crise urbana. São Paulo: Expressão Popular, 2015.

MIRANDA NETO, J. Q. Reassentamento da população urbana diretamente afetada pelo empreendimento hidrelétrico de Belo Monte em Altamira-PA. Revista Nacional de Gerenciamento de Cidades, Tupã, v. 2, n. 13, p. 43-57, 2014.

MIRANDA NETO, J. Q. ALVAREZ, W. P. Relatório Técnico sobre ocorrências de alagamento no bairro Independente 1 - Área da lagoa. Belém: UFPA, 2017.

MIRANDA NETO, J. Q; HERRERA, J. A. Altamira-PA: novos papéis de centralidade e reestruturação urbana a partir da instalação da UHE Belo Monte. Confins, Paris, n. 28, 2016. Disponível em: https://journals.openedition.org/ confins/11284. Acesso em: 17 dez. 2020.

NEGRI, S. M. Segregação sócio-espacial: alguns conceitos e análises. Coletâneas do Nosso Tempo, [s. l.], v. 8, n. 8, p. 129-156, 2010.

NORTE ENERGIA. Plano Básico Ambiental da Usina Hidrelétrica de Belo Monte. Altamira: Norte Energia S.A., 2011.

NORTE ENERGIA. Relatórios de Monitoramento Socioambiental Independente do Projeto UHE Belo Monte: 2014-2017. Altamira: Norte Energia S.A., 2017.

ONU. Relatório da ONU mostra população mundial cada vez mais urbanizada. ONU, [s. l.], 19 fev. 2019. Disponível em: https://news.un.org/pt/ story/2019/02/1660701. Acesso em: 28 nov. 2021.

ROCHA, G. M. Vilas e cidades e a Usina Hidrelétrica Tucuruí. In: CASTRO, E. (org.). Cidades na floresta. São Paulo: Annablume, 2008. p. 283-307.

SANTOS, M. O retorno do território. In: SANTOS, M.; SOUZA, M. A. A.; SILVEIRA, M. L. (org.). Território: globalização e fragmentação. 5. ed. São Paulo: Hucitec, 2002. p. 15-20.

SANTOS, M. A urbanização brasileira. São Paulo: EDUSP, 2005. 
SANTOS, M. Técnica, espaço e tempo: globalização e o meio técnico, científico, informacional. 5. ed. São Paulo: EDUSP, 2013.

SANTOS, M.; SILVEIRA, M. L. O Brasil: território e sociedade no início do século XXI. 6. ed. Rio de Janeiro: Record, 2008.

SMITH, N. Desenvolvimento desigual: natureza, capital e a produção de espaço. Rio de Janeiro: Bertrand Brasil, 1988.

SOUZA, M. J. L. ABC do desenvolvimento urbano. Rio de Janeiro: Bertrand Brasil, 2003.

SOUZA, M. J. L. Os conceitos fundamentais da pesquisa sócio-espacial. Rio de Janeiro: Bertrand Brasil, 2013.

TRINDADE JÚNIOR, S-C. C. Assentamentos urbanos e reestruturação metropolitana: o caso de Belém. GEOUSP: espaço e tempo (online), São Paulo, v. 2, n. 2, p. 39-52, 1998.

TRINDADE JÚNIOR, S-C. C. Cidades na floresta: os "grandes objetos" como expressões do meio técnico-científico informacional no espaço amazônico. Revista IEB, São Paulo, n. 51, p. 113-137, set./mar. 2010.

UMBUZEIRO, A. U. B.; UMBUZEIRO, U. M. Altamira e sua história. 4. ed. Belém: Ponto Press Ltda., 2012.

VILLAÇA, F. Espaço intra-urbano no Brasil. São Paulo: Studio Nobel, 1998. 